\title{
Aprendizagem significativa no ensino de cinética química através de uma oficina problematizadora
}

Matheus Campos de Castro mcastro@alunos.utfpr.edu.br orcid.org/0000-0002-9918-1491 Universidade Tecnológica Federal do Paraná (UTFPR), Apucarana, Paraná Brasil

\section{Mateus Siraque}

siraque@alunos.utfpr.edu.br orcid.org/0000-0003-2966-791X Universidade Tecnológica Federal do Paraná (UTFPR), Apucarana, Paraná, Brasil

Lilian Tatiani DusmanTonin liliandusman@utfpr.edu.br Orcid.org/0000-0002-8250-8064 Univerśdade Tecnologica Federal do (UTPR), Apucarana, Paraná,

\section{RESUMO}

O presente trabalho foi desenvolvido e aplicado pelos pibidianos de química e teve como objetivo o ensino de cinética química através de experimentos problematizados, baseado no modelo teórico da aprendizagem significativa. O trabalho consistiu na aplicação de cinco experimentos, todos acerca do conteúdo de cinética, com ênfase nos fatores que afetam a velocidade da reação. Os experimentos escolhidos foram: pasta de dente de elefante para demonstração do uso de catalisador; relógio de iodo para demonstrar o efeito da concentração; dissolução de comprimidos efervescente, para mostrar o efeito da superfície de contato e da temperatura, e as pulseiras de neon para demonstrar o efeito da temperatura. Antes da realização do experimento foram levantadas questões para analisar o conhecimento prévio dos alunos, e em seguida houve uma aula dialogada. Foram entregues junto aos roteiros a problematização dos experimentos e as questões para análise e avaliação do aprendizado. Os alunos, em um primeiro momento, executaram os experimentos sob a orientação dos pibidianos e responderam os questionários a respeito de cada experimento. $O$ uso da problematização dos experimentos, e de exemplos de situações do cotidiano dos alunos, despertou o interesse dos estudantes pelo conteúdo de cinética. Os mesmos conseguiram relacionar seus conhecimentos pré-existentes com os conceitos científicos envolvidos, levando a uma reorganização destes e adquirindo novos significados, ou seja, uma aprendizagem significativa. A presente oficina mostrou-se uma importante ferramenta de ensino, tornando o ensino de cinética química mais desafiador e reflexivo, permitindo o desenvolvimento do pensamento crítico do aluno.

PALAVRAS-CHAVE: Oficina temática. Ensino de Química. Problematização. Cinética Química. Velocidade de reação. 


\section{INTRODUÇÃO}

O Programa Institucional de Bolsa de Iniciação à Docência (PIBID) vem se tornando um importante instrumento de políticas públicas na qual há a valorização do magistério, possibilitando aos licenciandos a inserção no seu campo de trabalho desde o início da sua formação (GAMA, et al, 2013).

Documentos como Parâmetros Curriculares Nacionais trazem que o ensino de química deve desenvolver um conhecimento científico no aluno, assim compreendendo o mundo e podendo interferir na interpretação que diz respeito ao conhecimento químico. Porém isso só é possível quando a abordagem de química é feita de maneira contextualizada ao seu cotidiano (BRASIL, 1999).

Carlos (2011) afirma que dentro destas propostas metodológicas se enquadram as oficinas temáticas. E segundo Marcondes (2007) no desenvolvimento de uma oficina temática alguns aspectos precisam ser levados em conta: a escolha do tema, a experimentação e os conceitos químicos agregados à oficina. O tema a ser escolhido deve ser um tema no qual o aluno consiga contextualizar ao conhecimento científico, trazendo a possibilidade de formação de um cidadão ativo na sociedade e crítico. A experimentação escolhida tem que ser feita cuidadosamente, trazendo experimentos que desperte a curiosidade do aluno, e o mesmo consiga propor hipóteses e melhorar o entendimento das suas ideias. Já os conceitos devem ser aplicados de forma mais aprofundada, para que assim o aluno tenha uma aprendizagem mais efetiva, e consiga fazer uma conexão com o seu cotidiano.

O conteúdo de cinética química envolve o estudo da velocidade da reação e quais fatores podem influenciá-la. Estudar esse conteúdo de forma tradicional, por meio de aula expositiva e atrelado à resolução de exercícios desconsidera o conhecimento prévio existente no aluno tornando o conteúdo distante do seu cotidiano (LIMA, et al, 2000).

Estudos apontam que deve existir a contextualização no ensino de cinética química, logo deve-se criar alternativas inovadoras e uma aula mais atraente para o aluno com esse tema (JORAZIA et al, 2000). Segundo Cardoso e Colinvaux (2000), nos dias atuais é muito comum uma prática docente pautada na construção do conhecimento afim de um aprimoramento conceitual, porém sem ter uma contextualização ao dia a dia do estudante.

Segundo Marcondes (2008) "A contextualização no ensino é motivada pelo questionamento do que nossos alunos precisam saber de Química para exercer melhor sua cidadania". Sendo assim, os conteúdos abordados devem ter algum significado ao aluno, com cunho social, fazendo assim que o estudante tenha um interesse sobre o tema, provocando no aluno uma leitura mais crítica do mundo.

Partindo destes pressupostos, o objetivo do trabalho foi o de problematizar experimentos de cinética química, atrelando o conhecimento prévio do aluno ao conhecimento científico, baseado no modelo teórico da aprendizagem significativa, buscando estimular o interesse pelo conteúdo e a formar um cidadão mais reflexivo. 


\section{FUNDAMENTAÇÃO TEÓRICA}

A oficina temática procura tratar os conteúdos de forma mais contextualizada, junto com a interdisciplinaridade, envolvendo os alunos numa metodologia na qual os mesmos participam de forma mais ativa do seu processo de ensino-aprendizagem, construindo assim o seu próprio conhecimento (MARCONDES, 2008).

As oficinas temáticas são definidas como um recurso metodológico apropriado para a divulgação do conhecimento científico e promove atitudes e comportamentos favoráveis. Assim relacionando o conhecimento prévio ao conhecimento científico atrelados ao cotidiano, as oficinas contribuem para uma visão do mundo na qual os alunos possam contribuir com os conhecimentos abordados no seu dia a dia e assim construir um conhecimento mais efetivo (CACHAPUZ, et al., 2000). Além da valorização do conhecimento científico, as oficinas têm como propósito o desenvolvimento de habilidades cognitivas, como observar, descrever fenômenos químicos e registrar observações de maneira clara. Utilizam para isso diversos tipos de linguagens, comparando, classificando dados e fenômenos, analisando resultados experimentas, entre outros, assim elaborando conclusões baseadas na experimentação, aplicando o conhecimento construídos na interpretação das questões (SOUZA, et al.,2014).

O desenvolvimento e uso de temas para o ensino de química permite aos alunos uma abordagem mais ampla e contextualizada dos conhecimentos químicos, assim facilitando e atrelando o conhecimento prévio com o conhecimento novo. Sendo assim, as oficinas temáticas partem de um conjunto de experimentação na qual auxiliam a construção não somente de conceitos químicos, mas sim uma visão do mundo correlacionando o conhecimento químico ao seu dia a dia, favorecendo uma aprendizagem significativa (CACHAPUZ, et al, 2000).

Alguns questionamentos levantados pelos alunos provocam discussões de alto teor educacional, porém nem sempre são levadas em consideração pelos professores. Gera-se um diálogo não produtivo, pois um aluno que não pergunta, não elabora problemas e não problematiza (FREIRE, 1987).

Conhecer o conhecimento prévio dos alunos auxilia o trabalho docente na escolha de estratégias didáticas, que possibilitam buscar nesses conhecimentos, a interligação com o novo conhecimento a ser estudado e assimilado. Quando existe na estrutura cognitiva do aprendiz elementos que dão aporte para as interligações entre conhecimento prévio e o novo conhecimento adquirido pelo aluno, ocorre o que Ausebel et al, (1980) chama de aprendizagem significativa.

Neste caso, o conhecimento prévio que atrelou ao conhecimento novo adquirido, na teoria da aprendizagem significativa é chamado de subsunsor. É válido ressaltar que a aprendizagem significativa pode ocorrer por dois processos: o primeiro é chamado de diferenciação progressiva, processo na qual o conhecimento novo interage com o subsunsor e atrela a ele, levando a uma modificação ou diferenciação; o segundo processo é denominado de reconciliação integrativa, e ocorre quando os conceitos prévios se organizam e se relacionam, adquirindo novos significados (MOREIRA, 1988). desafiar o aluno a expor suas ideias sobre uma situação apresentada pelo 
professor. O objetivo principal é levar o aluno a sentir a necessidade de outros conhecimentos. O professor organiza os conhecimentos básicos para a compreensão do assunto tratado, aplica atividades para melhor entendimento, assim fazendo com que o aluno articule o conhecimento científico com a situação problematizada. Uma aula problematizada conduz o aluno a comparar situações do cotidiano com o conhecimento científico adquirido em sala de aula.

Bachelard (1996) afirma que o conhecimento científico é incorporado pelo esforço em problematizar a realidade e investigar seus aspectos desconhecidos. "Para o espírito científico, todo conhecimento é resposta a uma pergunta. Se não há pergunta, não pode haver conhecimento científico. Nada é evidente. Nada é gratuito. Tudo é construído" (p. 18).

A tarefa do professor é estimular o aluno, fazendo com que construa suas próprias ideias. Freire $(1987$, p. 70$)$ assegura: "Quanto mais se problematizam os educandos, como seres no mundo, tanto mais se sentirão desafiados, quanto mais obrigados a responder o desafio". Quando as aulas apresentam problematizações relacionadas ao cotidiano do aluno, este participa com mais interesse e segurança, apresentando suas ideias em torno do conteúdo do estudo e, ao mesmo tempo, exercitando seu pensamento crítico.

\section{METODOLOGIA}

No primeiro momento foi feita uma pesquisa acerca de oficina temática e sobre os experimentos a serem abordados. Essas pesquisas foram realizadas em artigos, livros didáticos de ensino superior e médio e em revistas de química. Logo após a pesquisa foram selecionados cinco experimentos diferentes para a abordagem do tema: pasta de dente de elefante e uso do catalisador; dissolução do comprimido efervescente e a superfície de contato, dissolução de comprimidos efervescentes e a temperatura; quimiluminescência das pulseiras de neon e a temperatura e relógio de lodo e o efeito da concentração.

Após a seleção dos cinco experimentos, foi elaborado o roteiro a ser utilizado na aula experimental e em seguida problematizou-se cada experimento com o objetivo de fazer conexão do conhecimento científico dos alunos com o seu diaa-dia.

Participaram da oficina 22 alunos do terceiro ano do ensino médio de diferentes turmas de um Colégio Estadual. Foram dispostos em grupos de dois a três alunos para realização de cada experimento. A oficina teve duração de três horas e foi realizada em um laboratório da Universidade (UTFPR).

Deu-se início na aula com um levantamento do conhecimento prévio dos estudantes, utilizando de perguntas abertas e com folhas para respostas individuais. As quatro questões foram:

a) O que é velocidade?

b) O que é velocidade de reação?

c) $\mathrm{O}$ que acelera uma velocidade de reação?

d) Dê exemplos de fatores que alteram a velocidade da reação no seu dia a dia. 
Os alunos tiveram 15 minutos para a elaboração de suas respostas e em seguida foram reservadas as folhas de respostas.

Dando sequência, foi realizada uma abordagem na forma de diálogo a respeito de cinética química com ênfase nos fatores que alteram a velocidade de reação. Foram discutidos vários conceitos para que o aluno reorganizasse suas novas ideias e estabelecesse uma relação com seus conhecimentos prévios.

Para o roteiro experimental foram elaboradas cinco questões problemas com uma ligação ao cotidiano do aluno:

1) Água oxigenada é um composto químico formado por $\mathrm{H}_{2} \mathrm{O}_{2}$, normalmente é utilizada na limpeza de ferimentos. Ao lavarmos o ferimento com a água oxigenada, percebemos a liberação de bolhas no local, isso ocorre por que o sangue e as células do tecido humano possuem uma enzima chamada Catalase. Enzimas são catalisadores biológicos. Os catalisadores cumprem a importante tarefa de fazer com que as moléculas presentes em uma reação reajam com uma velocidade maior. Assim, as bolhas formadas quando a água oxigenada entra em contato com o machucado provem do oxigênio liberado na reação. Explique a diferença entre as duas reações realizadas no experimento 1.

Para a realização do experimento 1 foi utilizado o seguinte procedimento:

Em uma proveta foram adicionados cerca de $10 \mathrm{~g}$ de lodeto de Potássio. Num béquer, adicionaram-se $20 \mathrm{~mL}$ de detergente, 6 gotas de corante e agitouse levemente, afim de homogeneizar a mistura. Depois, adicionou-se cerca $50 \mathrm{~mL}$ de Peróxido de Hidrogênio no béquer e agitou-se levemente. De forma rápida transferiu-se o conteúdo do béquer para a proveta. Observou-se a reação. Em uma segunda proveta, foram colocados $50 \mathrm{~mL}$ de Peróxido de Hidrogênio, $20 \mathrm{~mL}$ de detergente, 6 gotas de corante e agitou-se levemente, afim de homogeneizar a mistura. Observou-se a reação. Os alunos tiveram um tempo para a resolução da questão.

O experimento dois buscava trabalhar a influência da superfície de contato na velocidade da reação. Apresentou-se a seguinte questão problema:

2) Imagine a situação: Você vai a um restaurante e come tudo o que tem direito e depois acaba passando mal, necessitando de um antiácido. Como está passando mal e precisa que o remédio reaja rápido você usaria o comprimido ou o pó? Há uma diferença significativa entre os dois? Descreva a diferença entre os dois tipos

Segue procedimento para o experimento dois:

Colocaram-se aproximadamente $150 \mathrm{~mL}$ de água em dois béqueres e reservou-se. Pegou-se dois comprimidos efervescentes e com o auxílio do almofariz macerou-se um dos comprimidos. Logo após cronometrando-se o tempo adicionaram-se os dois comprimidos, o macerado e o inteiro, cada um em seu respectivo béquer, marcando-se o tempo que leva para dissolver em cada um dos casos (REIS, 2014). Porque o tempo foi diferente?

Após a realização do experimento os alunos dispuseram de um pequeno tempo para discutir e responder as questões referentes ao experimento trabalhado.

Os experimentos três e quatro tiveram o objetivo de trabalhar a influência da temperatura na velocidade da reação. Para o experimento três foram utilizados 
os mesmos reagentes do experimento dois e para o experimento quatro foram utilizadas pulseiras de neon com o objetivo de exemplificar a quimiluminescência.

A questão problematizadora para o experimento três foi:

3) Quando vamos cozinhar algum alimento, é conveniente levarmos ao fogo. Por que isso ocorre? Se deixar o arroz, por exemplo, sem o fogo ligado, ele vai cozinhar? E se deixar o fogo mais baixo, isso vai demorar mais tempo que se o fogo tiver alto? Ou o tempo será o mesmo? Utilizando essas informações e ligando ao experimento três, o que podemos observar?

O procedimento realizado está apresentado a seguir:

Colocaram-se aproximadamente $125 \mathrm{~mL}$ de água com gelo em um béquer, e $150 \mathrm{~mL}$ de água quente em outro. Adicionou-se ao mesmo tempo um comprimido efervescente em cada béquer, cronometrou-se e anotou-se o tempo para dissolução total. (REIS, 2014). Anote suas observações.

O experimento quatro foi assim problematizado:

4) Quem nunca foi para uma festa que fossem distribuídos acessórios como perucas e pulseiras de neon e levou um monte destas pulseiras para casa? Entretanto as pulseiras acabam perdendo seu brilho com o tempo e tem quem diga que se colocar na geladeira elas recarregam. Mas não the parece estranho isso? Usando esse princípio a pulseira deveria durar para sempre, mas na prática é isso que acontece? O que você acha que acontece?

Após o experimento você consegue descrever melhor essa situação?

Utilizando o procedimento descrito foi realizado o experimento 4:

Colocaram-se aproximadamente $300 \mathrm{~mL}$ de água em um béquer e reservouse. Em outro béquer adicionaram-se aproximadamente $300 \mathrm{~mL}$ de água quente e no terceiro béquer adicionaram-se aproximadamente $300 \mathrm{~mL}$ de água e gelo. Em seguida "quebrou-se" os bastões luminosos, a fim de ativar a coloração característica e os mesmos foram colocados em cada um dos béqueres. Após 1 minuto alterou-se os bastões de cada béquer. Repetiu-se esse procedimento três vezes. O que foi possível observar?

O Experimento cinco propôs a seguinte problematização:

5) Quando vamos ao salão de beleza, para fazer luzes ou mechas no cabelo, usa-se água oxigenada. O que ela faz com a coloração? Quanto maior o volume, mais claro o cabelo fica?

Para a realização do experimento foi preparada uma solução $A$ e $B$ de uso comum, sendo distribuída entre as bancadas para que todos os grupos executassem o experimento. Segue procedimento:

Solução A: Dissolveram-se 2,0 g de iodeto de potássio em $1 \mathrm{~L}$ de água.

Solução B: Ferveram-se $500 \mathrm{~mL}$ de água. Em seguida, adicionaram-se 2,0 g de amido e misturou-se bem. Quando essa solução esfriou, adicionaram-se 0,40 g de bissulfito de sódio e 1,7 mL de ácido sulfúrico. Por último, completou-se o volume para $1 \mathrm{~L}$ com água destilada. Adicionaram-se quantidades iguais das soluções num béquer de $500 \mathrm{~mL}$. 
Preparou-se outra solução de $\mathrm{A}$ usando $2,0 \mathrm{~g}$ de iodeto de potássio num volume de $500 \mathrm{~mL}$ de água e adicionando-se quantidades iguais das soluções $\mathrm{A} \mathrm{e}$ $B$ num béquer de $500 \mathrm{~mL}$.

Qual a variação da coloração?

No experimento relógio de iodo o que é possível observar? Quanto mais iodo, o que acontece? Isso influenciou em algo na reação?

Após a finalização do experimento com as elaborações de respostas por partes dos alunos, foi feita uma rápida revisão acerca de tudo o que foi estudado sobre cinética química e solicitado aos alunos que respondessem as mesmas questões iniciais, para que fosse possível realizar um estudo de como a oficina foi compreendida pelos alunos, criando uma conexão com seu conhecimento prévio e os novos aprendidos.

Para avaliar se os alunos tiveram uma aprendizagem significativa, foi levantada uma quinta questão: "Dê exemplos de seu cotidiano de fatores que alteram a velocidade da reação".

Após a finalização da experimentação foi proposto aos alunos, uma avaliação da oficina.

\section{RESULTADOS E DISCUSSÕES}

No início da oficina efetuou-se o levantamento do conhecimento prévio dos alunos com a ajuda de um questionário inicial, que contava com quatro questões. Para a classificação do conhecimento prévio do aluno utilizou-se de quatro categorias: não sabe, correto, confusa e incorreto.

Segundo RONCA (1994) o ponto inicial da teoria que Ausubel propõe é o conjunto de conhecimentos que o aluno traz consigo, ou seja, o seu conhecimento prévio. Por esse motivo se iniciou a oficina com um questionário para analisar esses conhecimentos.

Os dados das respostas para a primeira pergunta "O que é velocidade?" estão organizados no Quadro 1 a seguir.

Quadro 1: Respostas obtidas na primeira pergunta

\begin{tabular}{c|c}
\hline Categoria & Número de respostas \\
\hline Não sabe & 6 \\
\hline Correto & 6 \\
\hline Confusa & 2 \\
\hline Incorreto & 9 \\
\hline
\end{tabular}

Fonte: Autoria própria (2017).

Uma parte dos alunos deu uma resposta coerente, porém alguns deles responderam de maneira confusa:

Aluno 1: velocidade é a força do movimento.

Aluno 2: velocidade de um corpo.

Aluno 3: velocidade é uma forma de energia que locomove várias coisas. 
Podemos observar que houve uma relação com a força ou o tempo que demora. Alguns alunos também escreveram a fórmula da velocidade média, deixando de lado o conceito. Alguns estudantes responderam corretamente:

Aluno 5: velocidade é a rapidez que um corpo se movimenta.

Aluno 6: velocidade é o quão rápido o carro anda.

Pode-se observar que alguns alunos traziam o conceito de velocidade bem esclarecido. Outros fizeram conexões ao cotidiano como a diferença entre andar e correr, entre outras coisas.

Para a segunda pergunta 'O que é velocidade de reação?' houve uma confusão maior por parte dos alunos, provavelmente por se tratar de um termo químico, pouco usado em seu cotidiano. Os dados obtidos estão apresentados na Quadro 2:

Quadro 2: Respostas obtidas na segunda pergunta

\begin{tabular}{c|c}
\hline Categoria & Número de respostas \\
\hline Não sabe & 4 \\
\hline Correto & 7 \\
\hline Confuso & 11 \\
\hline Incorreto & 0 \\
\hline
\end{tabular}

Fonte: Autoria própria (2017)

Analisando a Quadro 2 podemos observar que metade da turma apresentou dificuldade em explicar o que é velocidade de reação.

Aluno 3: um tempo determinado para agir.

Aluno 8: reação é o processo que ocorre entre duas substâncias.

Aluno 10: é os reagentes que se movimentam e forma algo, e o tempo que demora.

Alguns alunos fizeram uma conexão ao cotidiano, trazendo exemplos do dia a dia, mas mesmo assim tiveram dificuldades na escrita:

Aluno 5: é o tempo que um ácido e uma base demoram para neutralizar.

Aluno 9: é quando tem dois reagentes e o tempo que eles demoram para formar o produto.

Analisando as respostas é possível observar que a maioria dos alunos associaram a velocidade de reação com o tempo.

A análise das respostas da terceira pergunta 'O que acelera uma velocidade de reação?' Estão na Quadro 3 abaixo:

Quadro 3: Respostas obtidas na terceira pergunta

\begin{tabular}{c|c}
\hline Categoria & Número de respostas \\
\hline Não sabe & 2 \\
\hline Correto & 8 \\
\hline Confuso & 8 \\
\hline Incorreto & 2 \\
\hline
\end{tabular}

Fonte: Autoria própria (2017)

Quatro alunos demonstraram não saber nada sobre o assunto, deixando em 
Aluno 1: As substâncias utilizadas.

Aluno 11: Energia.

Aluno 14: Energia térmica.

Alguns alunos responderam corretamente, e todos os oito alunos citaram a temperatura como único fator que altera a velocidade da reação:

Aluno 19: a temperatura.

Aluno 21: a diferença de temperatura.

Acredita-se que a temperatura foi citada pela maioria, por ser um fator do seu cotidiano.

Os dados obtidos para a quarta pergunta 'Dê exemplos de fatores que alteram a velocidade da reação no seu dia-a-dia' estão organizados na Quadro 4.

Quadro 4: Respostas obtidas para a quarta pergunta

\begin{tabular}{c|c}
\hline CATEGORIA & Número de respostas \\
\hline Não sabe & 4 \\
\hline Correto & 7 \\
\hline Confuso & 9 \\
\hline Incorreto & 2 \\
\hline
\end{tabular}

Fonte: Autoria própria (2017)

Os alunos tiveram dificuldades em responder essa pergunta, como por exemplo:

Aluno 17: energia solar.

Aluno 22: quando colocamos a roupa para secar no varal.

Aluno 15: quando esquentamos água, ela muda.

Aluno 18: quando congelamos a agua.

Alguns responderam de forma coerente, e a temperatura continuou sendo o único fator lembrado pelos alunos:

Aluno 5: o fogo quando cozinha o alimento.

Aluno 7: o fogo.

Aluno 9: a geladeira que conserva mais tempo o alimento.

Avaliando o conhecimento prévio dos estudantes pode-se observar que a maioria dos estudantes não conseguiu fazer uma conexão dos seus conhecimentos com o conceito abordado de forma clara.

Após os alunos responderem o questionário inicial, foi ministrada uma aula sobre o conteúdo de cinética química com ênfase nos fatores que alteram a velocidade da reação. Durante a aula, vários exemplos de fatores que alteram a velocidade de uma reação no cotidiano foram citados. Houve a participação dos alunos nas discussões, com questionamentos e inclusive citando exemplos e dialogando sobre o assunto.

Logo após a aula, foi realizado os experimentos e abordada a problematização dos experimentos. O primeiro experimento foi a pasta de dente de elefante, para poder demonstrar o efeito do catalisador na velocidade da reação. As respostas demonstraram que os alunos conseguiram entender que se usa o catalisador para aumentar a velocidade das reações, assim entendendo a 
diferença entre as duas reações realizadas na prática (com e sem iodeto de potássio).

Grupo 1: o iodeto de potássio que atuou como catalisador.

Grupo 3: a utilização do iodeto de potássio como catalisador, acelera a reação.

Grupo 5: foi essencial o iodeto que funciona como catalisador.

Grupo 4: o iodeto de potássio diminui energia de ativação.

Todos conseguiram associar o iodeto de potássio como catalisador, e que o mesmo acelera a velocidade da reação. Um dos grupos também fez a associação que o catalisador diminui a energia de ativação, conteúdo trabalhado no segundo ano, e que os alunos conseguiram relacionar com o experimento. Acredita-se que a situação problema apresentada contribuiu para o entendimento por parte do aluno do conceito envolvido pois conseguiram correlacionar com seu cotidiano.

O segundo experimento foi a verificação de como a superfície de contato pode influenciar na velocidade da reação. Novamente a problematização trazia algo do cotidiano do aluno, para que assim o conhecimento prévio do mesmo pudesse se atrelar ao conhecimento científico de maneira mais fácil. Podemos observar isso nas respostas a seguir:

Grupo 6: Em pó seria mais rápido a reação. A diferença é que em pó ele tem maior superfície de contato, e em comprimido menor.

Grupo 7: Em pó dissolve mais rápido, pois a superfície de contato é maior.

Grupo 3: O comprimido macerado (pó). Sim, percebemos uma diferença de 28 segundos. O comprimido inteiro se dissolve mais lentamente por possuir menor superfície de contato, já o macerado ocorre mais rápido, pois a superfície de contato é maior.

Grupo 4: o comprimido em pó aumenta a área de contato, então aumenta a velocidade de reação.

Podemos observar analisando as respostas, que todos os grupos conseguiram fazer uma associação que quanto maior a superfície de contato, maior a velocidade da reação, consequentemente o tempo de reação é menor. $A$ maior dificuldade encontrada na hora da resolução do experimento foi referente aos alunos entenderem que quanto menor o tamanho das partículas, maior é a superfície de contato, para isso durante o experimento recorremos a exemplos para que os mesmos conseguissem assimilar de maneira mais eficiente $o$ experimento.

Na sequência, o terceiro experimento investigou a influência da temperatura na dissolução do comprimido efervescente em água. As respostas obtidas foram a seguintes:

Grupo 2: a temperatura ajuda no procedimento, então a água quente acelera o cozimento do arroz, pois tem maior energia cinética, e aumenta o número de choques.

Grupo 4: podemos observar que quanto mais alto a temperatura ele cozinha mais rápido, e se a temperatura estiver baixa não irá cozinhar.

Grupo 7: a temperatura ajuda a cozinhar, ela é essencial, e quando aumenta a temperatura aumenta o número de choque, por isso a reação é mais rápida. 
Analisando as respostas dos alunos observamos que todos os grupos conseguiram responder de forma coerente, fazendo uma importante conexão entre a temperatura e o aumento de choques, e energia cinética. E logo, que quanto maior a temperatura, maior a velocidade de uma reação. Esse foi o fator no qual os alunos assimilaram de maneira mais fácil, pois conseguiram relacionar com fatos do seu cotidiano.

O experimento 4 tratou da influência da temperatura na quimiluminescência das pulseiras de neon. Para esse experimento e problematização a grande maioria dos alunos conseguiu elaborar uma resposta coerente e dentro do que se esperava:

Grupo 6: Com o passar do tempo e por estarem em um local com menor temperatura a luminosidade irá diminuir, com isso irá manter a luminosidade por mais tempo, porém com menor brilho.

Grupo 4: A temperatura mais alta acelera a reação, e a água fria faz com que a reação aconteça de forma mais lenta. Logo a temperatura influencia na velocidade da reação.

Grupo 1: a luminosidade da pulseira aumentava com o aumento da temperatura, porque quando aumenta a temperatura aumenta a velocidade da reação.

Em grande parte, os grupos conseguiram responder as perguntas, e relacionar que o fator temperatura altera a velocidade da reação acelerando ou retardando a mesma. Nessa questão, dois grupos deixaram em branco. Acreditamos que isso aconteceu devido a resposta ser parecida com a anterior, e se tratar do mesmo efeito.

Segundo (RONCA, 1994) a aprendizagem significativa ocorre por meio da ligação do conceito que o aluno já possui com o novo que the foi apresentado, e que a assimilação dos conhecimentos ocorra de um conceito amplo para um mais específico.

O último experimento denominado relógio de iodo fazia alusão ao efeito da concentração na velocidade da reação. Nessa problematização setenta e cinco por cento responderam corretamente, e conseguiram relacionar o conhecimento prévio existente.

Grupo 6: Ela age como um descolorante, quanto maior o volume (concentração) mais ela descolore. E no experimento podemos notar que ao adicionar uma concentração maior de iodo ela acontece mais rápida.

Grupo 7: Quanto mais iodo, mais concentrado e mais rápido a reação acontece porque tem mais choques, e isso quando vamos no salão quanto maior o volume, mais concentrada a água oxigenada é e mais ela descolore.

Grupo 4: Quanto mais concentrado a reação acontece mais rápido, por isso que quanto maior o volume da água oxigenada mais descolore.

Novamente conseguimos observar que o a maioria dos alunos conseguiu assimilar a problematização com o fator concentração e o que ela causa na velocidade da reação, associando seus conhecimentos prévios aos científicos e levando a uma aprendizagem significativa.

Os conhecimentos adquiridos pelos alunos durante a oficina foram de fato classificados como uma aprendizagem significativa, pois foram organizando hierarquicamente em uma sequência de fatores relacionados a um conceito amplo (RONCA, 1994). 
Após a aplicação dos experimentos e análise das respostas foi possível observar que quando se faz uma conexão com o conhecimento prévio do estudante atrelado a uma problematização presente em seu cotidiano, o mesmo tem uma aprendizagem significativa.

Logo após a aplicação dos experimentos, foi solicitado aos alunos que respondessem novamente as quatro questões iniciais, para assim podermos avaliar se os mesmos conseguiram assimilar o conteúdo de forma correta. Nas respostas foi possível notar que cerca de $90 \%$ dos alunos conseguiram responder de forma correta às questões.

Segue as respostas dos alunos para a pergunta um:

Aluno 2: é a rapidez que um corpo se movimenta.

Aluno 5: é a rapidez que o corpo está em movimento.

Aluno 12: é a rapidez que o corpo se move num determinado tempo.

Para a segunda pergunta os alunos fizeram uma conexão com a fórmula da velocidade média e explicando o que ocorre:

Aluno 11: rapidez que os reagentes se transformam em produto.

Aluno 10: é o tempo necessário que os produtos levam para formar reagente.

Aluno 12: é o tempo que a concentração dos reagentes leva para formar produtos.

Para a terceira pergunta os alunos conseguiram fazer uma ligação com os fatores evidenciados na experimentação:

Aluno 13: Temperatura, catalisador e concentração.

Aluno 20: Catalisador, concentração e temperatura.

Aluno 5: Temperatura, superfície de contato.

Para a quarta pergunta os alunos continuaram citando a temperatura de forma implícita:

$$
\begin{aligned}
& \text { Aluno 11: fogo. } \\
& \text { Aluno 17: fogo. } \\
& \text { Aluno 14: o gelo. }
\end{aligned}
$$

Segundo Ausubel (1980) a aprendizagem significativa é um processo cognitivo, no qual o conceito de mediação está presente, e para ocorrer o aluno tem que ter um conhecimento prévio, para que este se atrele ao novo adquirido. Assim, analisando as respostas, foi possível evidenciar que os alunos tiveram uma aprendizagem significativa, conseguindo atrelar seu conhecimento prévio ao cientifico, ou esclarecendo mais o conhecimento prévio existente.

$\mathrm{Na}$ pergunta 5, utilizada somente para avaliar o conhecimento adquirido pelos alunos, os mesmos deveriam citar exemplos de fatores que alteram a velocidade da reação no seu cotidiano, cerca de $80 \%$ citaram a temperatura:

Aluno 22: o fogo que usamos para aumentar a temperatura.

Aluno 18: a geladeira que abaixa a temperatura, e o fogo que aumenta. 
A grande maioria dos alunos conseguiu estabelecer uma conexão entre a temperatura que pode aumentar ou diminuir a velocidade da reação.

Segundo AUSUBEL (1965) "o domínio de conhecimentos mais amplos de uma determinada disciplina, influencia a longo prazo a performance do aluno naquela área do conhecimento". Observa-se que o fator temperatura manteve-se como o mais lembrado pelos alunos, porém, assim como propõe Ausubel esse conhecimento está mais amplo, mais difundido.

Por fim, a avaliação da oficina após a intervenção, demonstrou que os alunos reconheceram a eficácia da metodologia aplicada:

Aluno 10: foi muito interessante podemos ver a química de perto, e aprender mais.

Aluno 12: foi legal, as aulas de laboratório junto com algo que nós já sabemos fica mais fácil aprender.

Aluno 20: com a oficina conseguimos entender coisas que são difíceis de aprender.

Aluno 15: Gostei da oficina, pois consegui ver que os experimentos de laboratório estão presentes na minha vida.

\section{CONCLUSÕES}

A partir da oficina temática problematizadora para o ensino de cinética química podemos concluir que a sua aplicação despertou um grande interesse por parte dos alunos pelo assunto estudado. É possível observar que a problematização do conteúdo facilitou a conexão entre o conhecimento prévio e o conhecimento científico, levando a uma aprendizagem significativa. Esse tipo de atividade contribui para formar um aluno mais pensante, favorece o debate e ensina o mesmo a relacionar seus conhecimentos cotidianos aos conhecimentos científicos, demonstrando a importância da química no seu dia a dia. 


\title{
Significant learning in the teaching of
chemical kinetics through a problem-setting workshop
}

\begin{abstract}
The present work was developed and applied by the chemistry pibidians and had as objective the teaching of chemical kinetics through problematized experiments, based on the theoretical model of meaningful learning. The work consisted in the application of five experiments, all about the kinetic content, with emphasis on the factors that affect the speed of the reaction. The experiments selected were: elephant tooth paste to demonstrate the use of catalyst; iodine watch to demonstrate the effect of concentration; dissolving effervescent tablets, to show the effect of the contact surface and temperature, and neon bracelets to demonstrate the effect of temperature. Before the experiment was carried out, questions were raised to analyze the students' prior knowledge, and then there was a dialoguing class. The problem-solving of the experiments and the questions for analysis and evaluation of the learning were given together with the scripts. The students, at first, performed the experiments under the guidance of the pibidians and answered the questionnaires regarding each experiment. The use of the problematization of the experiments, and examples of situations of the students 'daily life, aroused students' interest in the kinetic content. They were able to relate their pre-existing knowledge with the scientific concepts involved, leading to a reorganization of these and acquiring new meanings, meaning meaningful learning. The present workshop has proved to be an important teaching tool, making the teaching of chemical kinetics more challenging and reflexive, allowing the student's critical thinking to develop.
\end{abstract}

KEYWORDS: Thematic Office. Chemistry teaching. Problematization. Chemical Kinetics. Speed of the reaction. 


\section{AGRADECIMENTOS}

À CAPES pela bolsa concedida.

\section{REFERÊNCIAS}

AUSUBEL, D. P.; NOVAK, J. D; HANESIAN, H. Psicologia educacional. Rio de Janeiro: Interamericana, 1980.

AUSUBEL, D. P. A cognitivestrutureviewofwordandconceptmearning. New York: Holt, RinehartAnd Winston, 1965.

BACHELARD, Gaston. A formação do espírito científico: contribuição para uma psicanálise do conhecimento. 5 a reimpressão. Rio de Janeiro - Brasil Contraponto EDITORA, 1996.

BRASIL. Secretaria de Educação Média e Tecnológica. Ministério da Educação e Cultura. Parâmetros curriculares nacionais para o ensino médio: ciências da natureza, matemática e suas tecnologias. Brasília: MEC/SEMTEC, V. 3, 1999

CACHAPUZ, A. F.; PRAIA, J. F.; JORGE, M. P. Perspectivas de ensino das ciências. Formação de professores/ciências. Porto: CEEC, 2000.

CARDOSO, P. S.; COLINVAUX, D. Explorando a motivação para estudar química. Química nova, V. 23, N. 3, 2000. P. 401-404. Disponível em:

<http://www.scielo.br/pdf/qn/v23n3/2827.pdf>. Acesso em 26 abr. 2017.

CARLOS, A. M. M.; SANTOS DOS, C. V.; CALDERAN, A. P.; BRAIBANTE, M. E. F. A química do papel como tema motivador para a realização de oficinas temáticas. Anais do 31 - encontro de debates sobre o ensino de química. RIO GRANDE, RIO GRANDE do SUL, 2011.

FREIRE, P. A PEDAGOGIA DO OPRIMIDO, 17a ED. RIO DE JANEIRO, PAZ E TERRA, 1987

GAMA, A. G. B., JÚNIOR, E. B. M., BARBOSA, E. M., NETO, F. P. S., TARGINO, K. C. F., SOUZA, M. C. M., FERNANDES, P. R. N. A importância do projeto pibid na formação dos alunos de licenciatura em química do IFRN câmpus-apodi. IX congresso de iniciação cientifica do IFRN. Rio Grande do Norte, 2013. Disponível em: <http://www2.ifrn.edu.br/ocs/index.php/congic/ix/paper/viewFile/1064/39 >. Acesso em 27 abr. 2017. 
HONORATO, M. A.; MION, R. A. A importância da problematização na construção e na aquisição do conhecimento científico pelo sujeito. Encontro nacional de pesquisa de educação em ciências. Florianópolis, 2009. Disponível em: <http://posgrad.fae.ufmg.br/posgrad/viienpec/pdfs/874.pdf >. Acesso em 26 abr. 2017

LIMA, J. F. L.; PINA, M. S. L.; BARBOSA, R. M. N.; JÓFILI, Z. M. S.; A contextualização no ensino de cinética química. Química nova na escola, N. 11, 2000. Disponível em <http://qnesc.sbq.org.br/online/qnesc11/v11a06.pdf >. Acesso em 27 abr. 2017

MARCONDES, M.E.R.; TORRALBO, D.; LOPES, E.S.L.; SOUZA, F.L.; AKAHOSHI, L.H.; CARMO, M.P.; SUART, R.C.; MARTORANO, S.A.A. oficinas temáticas no ensino público: formação continuada de professores. São Paulo: imprensa oficial do estado de São Paulo, 2007

MARCONDES, M.E.R. Proposições metodológicas para o ensino de química: oficinas temáticas para a aprendizagem da ciência e o desenvolvimento da cidadania. Em extensão. Uberlândia, 2008. Disponível em:< http://www.seer.ufu.br/index.php/revextensao/article/viewFile/20391/10861>. Acesso em 28 abr. 2017.

MOREIRA, M. A. Mapas conceituais e Aprendizagem Significativa. Adaptado da Revista Galáico Portuguesa de Sócio-Pedagogia e Sócio-Linguística, v. 23, 1988. p. 87-95. Disponível em: < http://www.if.ufrgs.br/ moreira/mapasport.pdf >. Acesso em 27 abr. 2017.

MOREIRA, M. A. O mapa conceitual como instrumento de avaliação da aprendizagem. Educação e Seleção, n. 10, 1984. p. 17-34.

PONTE LEAL, K; BARCELLOS, M. Prática dialógica e problematização em sala de aula: Um estudo de caso. - Atas do IX Encontro Nacional de Pesquisa em Educação em Ciências - IX ENPEC, Águas de Lindóia - SP, 2013. Disponível em: < http://www.nutes.ufrj.br/abrapec/ixenpec/atas/resumos/R1106-1.pdf >. Acesso em 28 abr. 2017

REIS, M; QUÍMICA, volume 1; 1 edição. Editora ática, São Paulo, 2014.

RONCA, A. C. C.; Teorias de ensino: A contribuição de David Ausubel. Temas em Psicologia, 1994. 
alunos do ensino básico buscando a alfabetização e divulgação cientifica de temas socialmente relevantes. XVII Encontro Nacional de Ensino de Química (XVII ENEQ), Ouro Preto, Minas Gerais, 2014. Disponível em:

<http://anaiseneq2014.ufop.br/pdf>. Acesso em 25 abr. 2017.

Recebido: 29 jul. 2017

Aprovado: $18 \mathrm{dez} .2017$

DOI: 10.3895/actio.v2n3.6848

Como citar:

CASTRO, M. C.; SIRAQUE ,M.; TONIN, L. T. D. Aprendizagem significativa no ensino de cinética química através de uma oficina problematizadora. ACTIO, Curitiba, v. 2, n. 3, p. 151-167, out./dez. 2017. Disponível em: <https://periodicos.utfpr.edu.br/actio>. Acesso em: XXX.

Correspondência:

Lilian Tatiani Dusman Tonin

Rua Marcílio Dias, 635, Apucarana, Paraná, Brasil.

Direito autoral: Este artigo está licenciado sob os termos da Licença CreativeCommons-Atribuição 4.0

Internacional.

(c) (1) 